\title{
Biochemical changes in patients with combined chronic schistosomiasis and viral hepatitis $\mathrm{C}$ infections
}

\author{
Fawzia A. Fahim ${ }^{\mathrm{a}}$, Amr Y. Esmat ${ }^{\mathrm{a}}$, \\ Gehan K. Hassan ${ }^{\mathrm{b}}$ and Abeer Abdel-Bary ${ }^{\mathrm{b}}$ \\ ${ }^{a}$ Department of Biochemistry, Faculty of Science, Ain \\ Shams University, Cairo, Egypt \\ ${ }^{\mathrm{b}}$ Department of Clinical Pathology, Faculty of \\ Medicine, Ain Shams University, Cairo, Egypt
}

Received 11 June 2000

This study was undertaken to assess the biochemical changes induced in chronic schistosomiasis and/or chronic HCV, as well as to pinpoint the most significant parameters which could be used as dependable indices for the differentiation of single and coupled infections with or without liver cirrhosis. The selected patients were allocated into 2 broad groups: GrII (Schistosomiasis) which was subdivided into 3 subgroups: GrII(a) schistosomal patients with hepatosplenomegaly; GrII(b) hepatosplenic schistosomal patients with decompensated liver cirrhosis; GrII(c) schistosomal patients with no organomegaly. GrIII (Combined) comprised 2 subgroups: GrIII(a) schistosomal-HCV infection with decompensated liver cirrhosis; GrIII(b) schistosomalHCV infection without liver cirrhosis. For statistical comparison normal healthy subjects were taken as a reference group (Gr I). Results showed that schistosomal patients without organomegaly manifested non significant changes in all studied parameters compared to normal controls. Highly significant elevations in serum ALT, AST, ALP and GGT activities were recorded in all other subgroups but the highest levels are reported in GrIIb. AST/ALT and direct/indirect bilirubin ratios were highest in GrIIIa $(1.17 \pm 0.26,1.54 \pm 0.37$, respectively). Serum total protein and albumin levels showed the highest reduction (33 and 59\%) concomitantly with the highest increase in $\gamma$-globulin level (75\%) in GrIII(a). Blood total iron was significantly reduced in $\operatorname{GrII}(a, b)(15.6$ and 12 $\%$ ), while it was paradoxically increased in GrIII(a) (8.8\%). One-way ANOVA test revealed that ALP, ALT, total protein, bilirubin, GGT and AST in this order are good discriminators between the different subgroups in GrII. On the other hand, ALT, AST, albumin, ALP, GGT, protein and direct bilirubin are the most significant indices to differentiate chronic schistosomiasis and the combined group with/or without liver cirrhosis.

Keywords: Schistosomiasis, hepatitis C, biochemistry

\section{Introduction}

Chronic liver diseases due to schistosomiasis and viral hepatitis are reported to be the most common diseases among Egyptian patients [2]. According to the estimation of WHO, schistosomiasis affects over 200 million people throughout the world and is responsible for 800,000 deaths per year $[8,21]$. On the other hand, the seroprevalence rate of $\mathrm{HCV}$ is reported to be 10 $20 \%$ among Egyptian volunteers and blood donors [11]. It is reported that although schistosomiasis is the commonest cause of minimal hepatic periportal fibrosis in Egypt, it is not the sole aetiological factor [1], as HCV seroprevalence is more pronounced among antischistosomal positive sera [20]. It is concluded that anti-HCV seropositivity is significantly associated with previous parenteral treatment for schistosomiasis [19].

Some studies reported a causative relationship between schistosomiasis and HCV. Antischistosomal therapy which was given as multiple injections in the past could have transmitted the HCV infection through contaminated needles and syringes [12,28]. Parenteral antischistosomal therapy is claimed to modulate the cytokine system in the liver which stimulates the multiplication of the virus [12].

Biochemical changes induced in patients suffering from either chronic schistosomiasis or chronic HCV infection have been reported $[4,16,17,30,36,38,43]$. However, no comprehensive biochemical study could be traced on chronic schistosomiasis combined with chronic HCV infection.

Thus, the main objective of this study was to highlight the biochemical changes induced in patients suf- 
fered from combined infection of chronic schistosomiasis and HCV. In addition, one-way ANOVA test was used to pinpoint the most significant parameters that could be considered as valuable indices in the differentiation of chronic schistosomiasis with or without hepatosplenomegaly associated with liver cirrhosis, and of combined infection with or without liver cirrhosis, in the follow up of the patients.

\section{Subjects, materials and methods}

\subsection{Cases}

60 Egyptian male patients aged 35-50 years suffering from chronic schistosomiasis or combined chronic schistosomal-HCV infection were chosen from the Inpatient Tropical Unit, Ain Shams University Hospital. For statistical comparison a reference group was established which comprised 10 healthy normal subjects.

For all chosen cases, complete urine and stool analyses were performed. In addition, detection of bilharzial antibody and determination of hepatitis B surface antigen (HBsAg), hepatitis B core antibody ( $\mathrm{HBcAb})$ and hepatitis $\mathrm{C}$ antibody (HCAb) were carried out. A full history was taken for each patient involving the period of bilharzial infection, previous appearance of jaundice, drug intake, smoking and blood transfusion. All patients were subjected to clinical examination of the abdominal organs and abdominal ultrasonography in the fasting state in both supine and lateral positions to assess the echogenicity of liver parenchyma, liver size, periportal thickening, portal and splenic vein diameters, spleen size and liver fibrosis.

\subsection{Plan of the work}

The selected cases were classified into 3 broad groups according to the following scheme:

Group I Normal Controls (Gr I N.C.): 10 normal healthy subjects.

Group II Schistosomiasis (GrII Schist): 30 patients with chronic schistosomiasis, who were further subdivided into 3 subgroups: II(a): 10 patients with hepatosplenomegaly, II(b): 10 hepatosplenic patients with decompensated liver cirrhosis, and II(c): 10 patients with no organomegaly.

Group III Schistosomal-HCV (Gr III Combined): 30 patients with chronic schistosomiasis and chronic HCV. This group was subdivided into 2 subgroups: III(a): 15 patients with decompensated liver cirrhosis, and III(b): 15 patients without liver cirrhosis.

\subsection{Blood sampling and methods}

Venous blood samples were taken from all cases in the fasting state and the following tests were assayed:

(1) Serum ALT, AST, ALP and GGT activities using the Synchrone CX5 autoanalyser system (Beckman, USA).

(2) Serum total protein [29], total bilirubin and its fractions [31] using kits provided from Diamond (Egypt).

(3) Electrophoresis of serum protein fractions on cellulose acetate strips (Helena Lab., USA) according to Ritzman et al. [42].

(4) Iron was extracted from blood according to Wong [46]. Total iron and serum magnesium levels were assessed according to Artiss et al. [5] and Gindler [26], respectively, using kits supplied from Elitech Diagnostics (France) and Deagle Diagnostics (USA).

(5) Serum urea and creatinine concentrations using the Synchrone CX5 automatic system (USA).

Results were analysed statistically according to Student's t test. The obtained laboratory findings were also subjected to one way analysis of variance (ANOVA test) to differentiate the different subgroups in each group [40].

\section{Results}

All results were statistically compared to normal controls (Gr.I).

Table 1 shows the changes in the serum levels of liver enzyme activities in patients suffered from chronic schistosomiasis without or with HCV (GrII \& GrIII). A very highly significant increase of serum ALT activity was recorded in all studied groups except for schistosomal patients without organomegaly (GrII c). Similarly, serum AST activity was significantly elevated in the previous groups. A statistically non significant change was recorded in AST/ALT ratio in all studied groups. A significantly drastic elevation was recorded in serum ALP activity in $\operatorname{GrII}(a, b), \operatorname{GrIII}(a, b)$, while it was slightly elevated in schistosomal patients without organomegaly $(36 \%, P<0.01)$. A significantly marked elevation was recorded in serum GGT activity in $\operatorname{GrII}(a, b), \operatorname{GrIII}(a, b)$, respectively. Non significant change was recorded in serum ALP and GGT activities in $\operatorname{GrII}(\mathrm{c})$.

Table 2 demonstrates the variations in serum total bilirubin and total protein levels and their fractions in 
Table 1

Changes of serum ALT, AST, ALP, GGT activities and AST/ALT ratio in all studied groups

\begin{tabular}{|c|c|c|c|c|c|}
\hline Group & $\begin{array}{c}\text { ALT } \\
\text { (IU/L) }\end{array}$ & $\begin{array}{c}\text { AST } \\
\text { (IU/L) }\end{array}$ & AST/ALT & $\begin{array}{c}\text { ALP } \\
\text { (IU/L) }\end{array}$ & $\begin{array}{l}\text { GGT } \\
\text { (IU/L) }\end{array}$ \\
\hline \multicolumn{6}{|l|}{ Gr I (N.C) } \\
\hline Range & $13-32$ & $13-31$ & $0.56-2.15$ & $25-50$ & $13-23$ \\
\hline $\mathrm{X} \pm \mathrm{S} . \mathrm{D}$ & $23.80 \pm 6.80$ & $21.91 \pm 6.90$ & $1.06 \pm 0.63$ & $35 \pm 8.96$ & $17.90 \pm 3.70$ \\
\hline \multicolumn{6}{|l|}{ Gr II Schist(a) } \\
\hline Range & $87-123$ & $64-101$ & $0.67-1.16$ & $149-200$ & $40-65$ \\
\hline$X \pm$ S.D & $100.20 \pm 11.50$ & $80.50 \pm 14.24$ & $0.81 \pm 0.19$ & $176 \pm 17.10$ & $53.70 \pm 90$ \\
\hline Change \% & 321 & 267 & 23.6 & 403 & 200 \\
\hline $\mathrm{P}<$ & 0.001 & 0.001 & N.S & 0.001 & 0.001 \\
\hline \multicolumn{6}{|l|}{ Gr II Schist(b) } \\
\hline Range & $86-125$ & $71-92$ & $0.74-0.88$ & $158-190$ & $64-90$ \\
\hline $\mathrm{X} \pm \mathrm{S} . \mathrm{D}$ & $102.60 \pm 14.27$ & $80.20 \pm 7.46$ & $0.79 \pm 0.10$ & $173.60 \pm 11.94$ & $76.40 \pm 9.58$ \\
\hline Change \% & 331 & 266 & 25.5 & 396 & 327 \\
\hline $\mathrm{P}<$ & 0.001 & 0.001 & N.S & 0.001 & 0.001 \\
\hline \multicolumn{6}{|l|}{ Gr II Schist(c) } \\
\hline Range & $18-36$ & $20-33$ & $0.83-1.22$ & $32-60$ & $12-27$ \\
\hline$X \pm$ S.D & $26.60 \pm 6.0$ & $25.80 \pm 4.60$ & $0.98 \pm 0.11$ & $47.60 \pm 7.82$ & $20.5 \pm 5.40$ \\
\hline Change \% & 11.8 & 17.8 & -7.55 & 36 & 14.52 \\
\hline $\mathrm{P}<$ & N.S & N.S & N.S & 0.01 & N.S \\
\hline \multicolumn{6}{|c|}{ Gr III Combined(a) } \\
\hline Range & $74-127$ & $90-143$ & $0.71-1.82$ & $151-192$ & $74-106$ \\
\hline$X \pm$ S.D & $102.61 \pm 16.10$ & $117 \pm 16.40$ & $1.17 \pm 0.26$ & $171.70 \pm 13.30$ & $87 \pm 11.30$ \\
\hline Change \% & 331 & 434 & 10.4 & 391 & 386 \\
\hline $\mathrm{P}<$ & 0.001 & 0.001 & N.S & 0.001 & 0.001 \\
\hline \multicolumn{6}{|c|}{ Gr III Combined(b) } \\
\hline Range & $173-228$ & $115-137$ & $0.64-0.70$ & $178-281$ & $88-125$ \\
\hline$X \pm$ S.D & $192.10 \pm 16.80$ & $129.70 \pm 10.40$ & $0.67 \pm 0.03$ & $222.20 \pm 3.70$ & $105.10 \pm 14.50$ \\
\hline Change $\%$ & 707 & 492 & -36.8 & 535 & 487 \\
\hline $\mathrm{P}<$ & 0.001 & 0.001 & N.S & 0.001 & 0.001 \\
\hline
\end{tabular}

all studied groups. Serum levels of total, direct and indirect bilirubin showed a highly significant increase in $\operatorname{GrII}(a, b)$ and GrIII(a,b). Direct/indirect bilirubin ratio was significantly increased in GrII (b) and GrIII (b) only. A significant reduction in serum total protein and albumin concentrations was recorded in all studied groups except for schistosomal patients without organomegaly (GrIIc). Serum $\alpha_{1}$-globulin level manifested a significant reduction in $\operatorname{GrII}(b)$ and $\operatorname{GrIII}(a)$ only. Serum $\alpha_{2}$ and $\beta$ globulins were significantly decreased in GrII(a), GrII(b) and GrIII(a). Serum $\gamma$ globulin level showed a significant elevation in $\operatorname{GrII}(a, b)$ and GrIII (a,b). Patients of GrII(c) showed non significant change in all globulin fractions.

Table 3 illustrates that serum urea level was significantly increased in GrII(b), GrIII(a). Serum creatinine concentration was highly elevated in GrIII(a) only. A statistically non significant change was recorded in serum magnesium level in all studied groups. Blood total iron showed a slight but significant increase $(8.8 \%, \mathrm{P}<0.01)$ in combined patients with liver cirrhosis (GrIIIa), but in contrast was reduced in hepatosplenic schistosomal patients with or without liver cirrhosis (GrIIa,b).
Table 4 shows the one-way ANOVA test which compares between the different subgroups in each group. The parameters with significant F-ratios were sorted in a descending order. In the first set of analyses, out of the 15 significant parameters obtained ALP, ALT, total protein, total bilirubin, GGT and AST could be considered as valuable indices in the follow up of chronic liver diseases and as good discriminators between chronic schistosomiasis without or with hepatosplenomegaly associated with decompensated liver cirrhosis (GrIIa,b,c) as they showed the highest Fratios. In the second set of statistical analyses, ALT, AST, albumin, ALP, GGT, total protein and direct bilirubin were the best markers in the differentiation of chronic schistosomiasis (GrIIc) and the combined group with or without decompensated liver cirrhosis (GrIIIa,b).

\section{Discussion}

Transaminases are sensitive indicators of liver cell injury and most helpful in recognizing acute hepatocellular diseases. They are also considered among the first 
Table 2

Changes of serum total bilirubin and protein and their fractions in all studied groups

\begin{tabular}{|c|c|c|c|c|c|c|c|c|c|c|}
\hline Group & $\begin{array}{c}\text { T. Bilirubin } \\
(\mathrm{mg} / \mathrm{dl})\end{array}$ & $\begin{array}{c}\text { Dir. Bil. } \\
(\mathrm{mg} / \mathrm{dl})\end{array}$ & $\begin{array}{c}\text { Ind. Bil. } \\
(\mathrm{mg} / \mathrm{dl})\end{array}$ & Dir/Ind.Bil & $\begin{array}{l}\text { T. Protein } \\
(\mathrm{g} / \mathrm{dl})\end{array}$ & $\begin{array}{l}\text { Albumin } \\
(\mathrm{g} / \mathrm{dl})\end{array}$ & $\begin{array}{c}\alpha_{1}-\mathrm{glob} \\
(\mathrm{g} / \mathrm{dl})\end{array}$ & $\begin{array}{c}\alpha_{2}-\mathrm{glob} \\
(\mathrm{g} / \mathrm{dl})\end{array}$ & $\begin{array}{c}\beta \text {-glob } \\
(\mathrm{g} / \mathrm{dl})\end{array}$ & $\begin{array}{c}\gamma \text {-glob } \\
(\mathrm{g} / \mathrm{dl}) \\
\end{array}$ \\
\hline \multicolumn{11}{|l|}{ Gr I (N.C) } \\
\hline Range & $0.36-0.85$ & $0.07-0.23$ & $0.29-0.63$ & 0.56 & $6-7.50$ & $3.30-4.20$ & $0.10-0.40$ & $0.50-0.90$ & $0.60-1.00$ & $0.70-1.40$ \\
\hline$X \pm$ S.D & $0.59=$ & $0.15 \pm 0.06$ & $0.45 \pm 0.13$ & 0.36 & $7 \pm 0.52$ & $3.90 \pm 0.26$ & $0.24 \pm 0.12$ & $0.70 \pm 0.15$ & $0.90 \pm 0.14$ & $1.20 \pm 0.21$ \\
\hline \multicolumn{11}{|c|}{ Gr II Schist(a) } \\
\hline Range & $1.3-1.93$ & $0.28-0.58$ & $0.97-1.35$ & $0.27-0.48$ & $5.60-6.50$ & $2.80-3.80$ & $0.10-4.0$ & $0.30-0.60$ & $0.50-0.80$ & $1.60-2$ \\
\hline$X \pm$ S.D & $1.47 \pm 0.20$ & $0.40 \pm 0.10$ & $1.07 \pm 0.11$ & $0.38 \pm 0.07$ & $6.1 \pm 0.29$ & $3.10 \pm 0.30$ & $0.19 \pm 0.10$ & $0.44 \pm 0.12$ & $0.62 \pm 0.09$ & $1.77 \pm 0.16$ \\
\hline Change $\%$ & 149 & 163.2 & 138 & 5.50 & -13 & -20.50 & -20.83 & -37 & -31.10 & 47.50 \\
\hline $\mathrm{P}<$ & 0.001 & 0.001 & 0.001 & & 0.001 & 0. & N.S & 0.001 & 0.001 & 0.001 \\
\hline \multicolumn{11}{|c|}{ Gr II Schist(b) } \\
\hline Range & $1.88-$ & 1.71 & -1.52 & & 4.70 & $2-$ & U & 50 & $0.40-0.60$ & $1.60-1.90$ \\
\hline $\mathrm{X} \pm \mathrm{S} . \mathrm{D}$ & $2.18 \pm 0.30$ & $0.96 \pm 0.43$ & $1.22 \pm 0.21$ & $0.86 \pm 0.52$ & $4.9 \pm 0.15$ & $2.16=$ & $0.16 \pm 0.08$ & $0.37 \pm 0.08$ & $0.52 \pm 0.08$ & $1.74 \pm 0.11$ \\
\hline Change $\%$ & .5 & & 171 & & -30 & -4 & -33.30 & -46 & -42.20 & 45 \\
\hline $\mathrm{P}<$ & 0.001 & 0.001 & 0.001 & 0.001 & 0.001 & 0.001 & 0.05 & 0.001 & 0.001 & 0.001 \\
\hline \multicolumn{11}{|c|}{ Gr II Schist(c) } \\
\hline Range & 0.37 & -0.29 & 0.51 & & 6.30 & 3.2 & & & $0.60-0.90$ & .40 \\
\hline $\mathrm{X} \pm \mathrm{S} . \mathrm{D}$ & $0.57 \pm 0.09$ & $0.19 \pm 0.08$ & $0.37 \pm 0.08$ & $0.55 \pm 0.28$ & $6.7 \pm 0.24$ & $3.70=$ & $0.21 \pm 1.0$ & $0.72 \pm 0.12$ & $0.81 \pm 0.11$ & $1.31 \pm 0.10$ \\
\hline Change \% & -3.4 & 25 & 17.80 & 53 & -4.30 & -5.10 & -12.50 & 2.90 & -11 & 8.30 \\
\hline $\mathrm{P}<$ & N.S & N.S & N.S & N.S & N.S & N.S & N.S & N.S & N.S & N.S \\
\hline \multicolumn{11}{|c|}{ Gr III Combined(a) } \\
\hline Range & $1.74-4.92$ & -1.91 & $1.31-3.01$ & & $3.90-$ & & & & $0.30-0.60$ & $0-2.50$ \\
\hline $\mathrm{X} \pm \mathrm{S} . \mathrm{D}$ & $2.70 \pm 0.94$ & $0.97 \pm 0.54$ & $1.73 \pm 0.50$ & $0.54 \pm 0.24$ & $4.70 \pm 0.33$ & $1.61 \pm 0.31$ & $0.15 \pm 0.05$ & $0.41 \pm 0.08$ & $0.45 \pm 0.09$ & $2.10 \pm 0.21$ \\
\hline Change \% & & & 284 & 50 & -33 & -59 & -37.50 & -41.4 & -50 & 75 \\
\hline $\mathrm{P}<$ & 0.001 & 0.001 & 0.001 & N.S & 0.001 & 0.001 & 0.05 & 0.001 & 0.001 & 0.001 \\
\hline \multicolumn{11}{|c|}{ Gr III Combined(b) } \\
\hline Range & $3.93-7.02$ & $2.70-4.43$ & $1.49-2.89$ & $1.12-2.24$ & $5.80-6.80$ & $2.80-3.50$ & $0.10-0.30$ & $0.40-0.90$ & $0.60-1.10$ & $1.20-1.60$ \\
\hline $\mathrm{X} \pm \mathrm{S} . \mathrm{D}$ & $5.47 \pm 1.10$ & $3.30 \pm 0.71$ & $2.20 \pm 0.50$ & $1.54 \pm 0.37$ & $6.30 \pm 0.31$ & $3.17 \pm 0.22$ & $0.21 \pm 0.06$ & $0.64 \pm 0.15$ & $0.84 \pm 0.13$ & $1.40 \pm 0.11$ \\
\hline Change $\%$ & 827 & 2071 & 389 & 328 & -10 & -18.72 & -12.50 & -8.60 & -7.0 & 17 \\
\hline $\mathrm{P}<$ & 0.001 & 0.001 & 0.001 & 0.001 & 0.01 & 0.001 & N.S & N.S & N.S & 0.05 \\
\hline
\end{tabular}

laboratory abnormalities detected in the early phase of viral hepatitis [27,33]. Results obtained from this study demonstrate that combination of chronic schistosomiasis and viral hepatitis C (GrIII) manifested the highest elevation in serum levels of ALT and AST activities. It is noteworthy that the sharp rise of serum ALT and AST activities is more pronounced in the combined patients without liver cirrhosis (GrIIIb) and amounted to about 8 and 6 fold, respectively. A lesser increase of about 4 and 5 fold was recorded in the combined patients with decompensated liver cirrhosis (GrIIIa) (Table 1). The mechanism of hepatocyte and bile duct injury that occurs with HCV infection is unknown, but it may be due to a combination of two mechanisms, direct cytopathic effect of HCV and immune-mediated cell injury triggered by HCV [24].

Serum AST/ALT ratio is important to differentiate acute and chronic viral hepatitis. It is reported that AST/ALT ratio is a dependable marker of fibrosis stage and cirrhosis and that its value is significantly decreased below 1 in acute NANB hepatitis including HCV, while in chronic viral hepatitis although AST/ALT ratio is slightly decreased, yet it is still more than 1 [45]. Data presented in Table 1 illustrate that serum AST/ALT ratio showed non significant decrease in all studied groups, compared to normal controls, yet the highest value is recorded in the combined group with liver cirrhosis (GrIIIa) $(1.17 \pm 0.26)$. Michielsen et al. [38] attributed the elevation in AST/ALT ratio in case of cirrhosis to the higher rise of serum AST activity probably because this cytosolic and mainly mitochondrial enzyme is present in higher quantities in the liver, compared to the cytosolic ALT and thus more is released in tissue damage. In our opinion, the heart may be involved secondarily to liver affection in case of severe liver damage resulting in higher serum AST level.

Serum ALP enzyme which is situated principally in the canalicular and sinusoidal membranes manifested a significantly marked elevation in the hepatosplenic schistosomal patients with or without cirrhosis (GrIIa,b), while it is slightly elevated in schistosomal patients with no organomegaly (Table 1). However, the greatest increase in serum ALP activity is reported in the combined group without liver cirrhosis (GrIIIb) (535\%, $P<0.001)$.

El-Ridi et al. [17] stated that schistosomiasis gives rise to a high serum ALP activity compared to the control group, but a marked increase is obtained in the ascitic patients and those with hepatosplenomegaly. 
Table 3

Changes of serum magnesium, blood total iron, serum urea and creatinine in all studied groups

\begin{tabular}{|c|c|c|c|c|}
\hline Groups & $\begin{array}{c}\mathrm{Mg} \\
(\mathrm{mg} / \mathrm{dl})\end{array}$ & $\begin{array}{c}\text { T.Fe } \\
\text { (ug/dl) }\end{array}$ & $\begin{array}{c}\text { Urea } \\
(\mathrm{mg} / \mathrm{dl})\end{array}$ & $\begin{array}{c}\text { Creatinine } \\
(\mathrm{mg} / \mathrm{dl})\end{array}$ \\
\hline \multicolumn{5}{|l|}{ Gr I (N.C) } \\
\hline Range & $1.60-2.50$ & $46.90-53.90$ & $19.30-40.70$ & $0.27-0.72$ \\
\hline$X \pm$ S.D & $2.10 \pm 0.30$ & $50.20 \pm 2.10$ & $30.40 \pm 8.37$ & $0.49 \pm 0.13$ \\
\hline \multicolumn{5}{|l|}{ Gr II Schist(a) } \\
\hline Range & $1.40-2.30$ & $34.30-48.80$ & $21.41-49.20$ & $0.35-0.70$ \\
\hline$X \pm$ S.D & $1.85 \pm 0.30$ & $42.25 \pm 4.92$ & $35.19 \pm 8.80$ & $0.52 \pm 0.12$ \\
\hline Change $\%$ & -12 & -15.60 & 15.75 & 6.10 \\
\hline $\mathrm{P}<$ & N.S & 0.001 & N.S & N.S \\
\hline \multicolumn{5}{|l|}{ Gr II Schist(b) } \\
\hline Range & $1.50-2.40$ & $37.30-49.60$ & $39.40-51$ & $0.39-1.20$ \\
\hline$X \pm$ S.D & $2 \pm 0.39$ & $44.18 \pm 4.76$ & $44.68 \pm 5.00$ & $0.70 \pm 0.32$ \\
\hline Change $\%$ & -4.8 & -12 & 47 & 43 \\
\hline $\mathrm{P}<$ & N.S & 0.01 & 0.01 & N.S \\
\hline \multicolumn{5}{|l|}{ Gr II Schist(c) } \\
\hline Range & $1.50-2.30$ & $42.10-51.40$ & $19.20-44.90$ & $0.46-0.70$ \\
\hline$X \pm$ S.D & $1.90 \pm 0.30$ & $48 \pm 3.44$ & $32.10 \pm 7.70$ & $0.56 \pm 0.08$ \\
\hline Change $\%$ & -9.52 & -4.4 & 5.59 & 14.30 \\
\hline $\mathrm{P}<$ & N.S & N.S & N.S & N.S \\
\hline \multicolumn{5}{|c|}{ Gr III Combined(a) } \\
\hline Range & $1.70-2.40$ & $47.70-67.60$ & $30.60-65.10$ & $0.53-1.95$ \\
\hline$X \pm$ S.D & $2.10 \pm 0.22$ & $54.60 \pm 5.90$ & $47.91 \pm 10.80$ & $1.10 \pm 0.50$ \\
\hline Change $\%$ & 0 & 8.80 & 58 & 124 \\
\hline $\mathrm{P}<$ & N.S & 0.01 & 0.001 & 0.001 \\
\hline \multicolumn{5}{|c|}{ Gr III Combined(b) } \\
\hline Range & $1.70-2.50$ & $43.81-51.80$ & $21.10-49.20$ & $0.48-0.72$ \\
\hline$X \pm$ S.D & $2.10 \pm 0.30$ & $48.20 \pm 2.30$ & $34.90 \pm 8.50$ & $0.60 \pm 0.11$ \\
\hline Change $\%$ & 0 & -3.90 & 14.80 & 22.40 \\
\hline $\mathrm{P}<$ & N.S & N.S & N.S & N.S \\
\hline
\end{tabular}

Serum GGT activity is a microsomal enzyme of the biliary canalicular membrane that is markedly raised in acute parenchymal damage from any cause. It is used to confirm that the rise in ALP is hepatic in origin [41]. Similar to ALP, serum GGT activity is remarkably elevated in all studied groups, with the exception of schistosomal patients with no organomegaly (GrIIc). A dramatic increase in serum GGT activity is recorded in the combined group without liver cirrhosis (Table 1). Our results are in line with those of Abdel-Rahman et al. [3] and El-Rouby et al. [18], who reported that serum GGT activity lies within the normal range in early schistosomal infection, and is significantly increased in hepatosplenic schistosomiasis, and that higher levels of the enzyme are observed in cases with mixed hepatic pathology. Also, Liehr et al. [34] and Mathurine et al. [37] affirmed a minor elevation in serum GGT activity in chronic HCV patients. From our findings it is suggested that the marked rise in serum ALP and GGT activities is mainly due to the hepatosplenic schistosomal disease rather than chronic HCV. This is in line with Coodley [10], who reported that elevations in serum GGT and ALP activities may be seen if there is a cholestatic component to the chronic hepatitis. Moreover, Sheth et al. [45] reported that in $\mathrm{HCV}$ infection, serum ALP activity is only 1.5 times the upper limit of the normal range.

Serum total, direct and indirect bilirubin levels are significantly increased in all studied groups with the exception of schistosomal patients without organomegaly, yet the highest increase is recorded in the combined group (Table 2). It is worth mentioning that the elevation in the total bilirubin concentration is mainly ascribed to the direct fraction which is more pronounced in the combined group without liver cirrhosis (GrIIIb), except for hepatosplenic schistosomal subgroup (GrIIa) in which the increase in both bilirubin fractions is equal. This observation accounts for the highly significant direct/indirect bilirubin ratio $(1.54 \pm 0.37)$, compared to normal controls $(0.36 \pm 0.15)$.

Our findings are in agreement with those of Sherlock [44] and El-Guinidy et al. [14], who reported that elevation in serum total bilirubin level in patients with active schistosomiasis and liver cirrhosis or with chronic viral hepatitis infection is mainly ascribed to the direct fraction due to decreased excretion or backward leakage of the pigment. 
Table 4

One way ANOVA test showing the significant parameters among all studied parameters in the different subgroups

\begin{tabular}{|c|c|c|c|c|c|}
\hline \multicolumn{3}{|c|}{ Test (1) } & \multicolumn{3}{|c|}{ Test (2) } \\
\hline Parameter & F- ratio & $\mathrm{P}$ value $<$ & Parameter & F-ratio & $\mathrm{P}$ value $<$ \\
\hline ALP & 326.53 & 0.001 & ALT & 338.4 & 0.001 \\
\hline ALT & 150.41 & 0.001 & AST & 223.8 & 0.001 \\
\hline T.P. & 149.00 & 0.001 & ALB & 207.7 & 0.001 \\
\hline T. Bil. & 136.44 & 0.001 & ALP & 173.13 & 0.001 \\
\hline GGT & 117.06 & 0.001 & GGT & 164.70 & 0.001 \\
\hline AST & 106.30 & 0.001 & T.P. & 162.65 & 0.001 \\
\hline Ind. Bil & 96.44 & 0.001 & Dir. Bil & 101.85 & 0.001 \\
\hline ALB & 95.26 & 0.001 & T. Bil & 90.70 & 0.001 \\
\hline$\gamma$-globulin & 38.05 & 0.001 & $\gamma$-globulin & 84.75 & 0.001 \\
\hline$\alpha_{2}$ globulin & 28.14 & 0.001 & Ind. Bil. & 55.68 & 0.001 \\
\hline$\beta$-globulin & 24.31 & 0.001 & $\beta$-glboulin & 50.47 & 0.001 \\
\hline Dir Bil. & 23.00 & 0.001 & Dir/Ind. Bil. & 41.21 & 0.001 \\
\hline Urea & 7.97 & 0.001 & $\alpha_{2}$ globulin & 23.47 & 0.001 \\
\hline AST/ALT & 7.20 & 0.01 & AST/ALT & 21.48 & 0.001 \\
\hline \multirow[t]{3}{*}{ Dir./Ind Bil } & 4.95 & 0.05 & Urea & 10.22 & 0.001 \\
\hline & & & Creatinine & 10.18 & 0.001 \\
\hline & & & $\mathrm{T}-\mathrm{Fe}$ & 9.05 & 0.001 \\
\hline
\end{tabular}

Test (1) refers to comparison between subgroups II (a \& b \& c).

Test (2) refers to comparison between subgroups IIc \& III(a \& b).

Serum total protein and albumin levels are significantly reduced in all studied groups, with the exception of schistosomal patients without organomegaly (GrIIc). The greatest reduction is observed in the cirrhotic patients with a single or dual infection (GrIIa, GrIIIa) which indicates the decreased ability of the liver to synthesize proteins at a normal rate (Table 2). It has been reported that serum albumin level is significantly decreased in hepatosplenic schistosomiasis and in chronic $\mathrm{HCV}$ and that its level provides an excellent indication of the severity of chronic liver disease [30,35].

Because of the dominant role of the liver in plasma protein synthesis, variations in serum protein components in schistosomiasis have been reported, with inconsistent results. Some studies reported on the elevation in $\alpha_{1}$-globulin which indicates that the liver parenchyma is not seriously affected since in cases of liver cell damage, the $\alpha_{1}$-globulin fraction is known to diminish $[4,15,22,39]$, others reported no significant change in the same fraction in schistosomiasis [25]. However, hypergammaglobulinaemia is a well documented feature of schistosomiasis [9]. In the present study, electrophoresis of serum protein fractions revealed that and $\alpha_{1}, \alpha_{2}$ and $\beta$ globulins are significantly decreased in the subgroups with decompensated liver cirrhosis (GrIIb \& GrIIIa) which indicates liver parenchyma injury. On the contrary, $\gamma$ globulin level is significantly increased in all studied groups, with the exception of schistosomal patients with no organomegaly (GrIIc). The highest increase of serum $\gamma$ globulin level is recorded in the combined group with liver cirrhosis (GrIIIa). Increased serum immunoglobulins in patients with schistosomiasis are reported to be due to immunologic stimulation of the reticuloendothelial cells (RE) in hepatic sinusoids by schistosomes or their eggs. This was evidenced by identification of antischistosomal antibodies in the $\operatorname{IgM}$ and $\operatorname{IgG}$ fractions which are the major constituents in the $\gamma$ globulin fraction [9]. Antibodies directed against antigens of the normal chronic flora account for much of the increased serum immunoglobulins in patients with cirrhosis. In cirrhosis, these antigens are not taken up and degraded by hepatic RE cells as they normally are, but reach lymphoid tissue outside the liver, where they elicit an antibody response [6].

Blood total iron concentration is significantly decreased in hepatosplenic schistosomal patients with or without liver cirrhosis (GrIIa,b). On the contrary, it is slightly increased in the combined group with liver cirrhosis (GrIIIa, Table 3). These results are reported herein for the first time to the best of our knowledge and are supported by the findings of Davis [13], who stated that a common primary sign of hepatosplenic schistosomal disease is haematemesis from gastro-oesophageal varcies and the patients have classical signs of acute blood loss and that melaena may follows in many cases. Farinati et al. [23] reported that HCV-positive patients have a trend toward iron overload. Also, Balistreri and Rej [7] documented an increase in iron stores within the hepatocytes and the RE cells in association with 
variable fibrosis and cirrhosis, where total body iron may be as high as 50-60 g. The authors attributed this observation to the inability of the damaged hepatocytes to take up iron or retain ferritin.

To assess the kidney function of the studied patients, serum urea and creatinine concentrations were determined. Serum urea level is significantly increased in cirrhotic patients of both groups (GrIIb and GrIIIa, Table 3 ). Serum creatinine concentration is significantly increased in the combined group with liver cirrhosis only (Gr IIIa). Our data are in line with those of Johnson et al. [32], who reported that patients with advanced liver disease, such as HCV have renal problems and that the mean serum creatinine level reaches $1.7 \mathrm{mg} / \mathrm{dl}$.

In conclusion, results obtained from this study affirm that combination of chronic schistosomiasis and $\mathrm{HCV}$ infection aggravates the liver dysfunction. This is demonstrated by the significantly more pronounced elevations in the serum levels of liver enzymes activity, especially in the non cirrhotic patients, and the augmented reduction in the serum albumin and total protein concentrations in case of cirrhotic patients. In addition, this study points out the importance of some biochemical markers in the follow up and discrimination between hepatosplenic schistosomal disease with or without liver cirrhosis (ALP, ALT, total protein, total bilirubin, GGT and AST), as well as single chronic schistosomiasis and the combined infection with or without liver cirrhosis (ALT, AST, albumin, ALP, GGT, total protein and direct bilirubin).

\section{Acknowledgement}

The authors acknowledge the sincere cooperation of Dr. Mohamed A.Shaker, Associate Professor of Tropical Medicine, Faculty of Medicine, Ain Shams University for choosing the cases of this study.

\section{References}

[1] S. Abdel-Kader, M. Amin and H. Hamdy, Causes of minimal hepatic periportal fibrosis present in Egypt, J. Egypt. Soc. Parasitol. 27 (1997), 919-924.

[2] M.M. Abdel-Rahman, M.S. El-Hakim and M.K. Ahmed, Cytophotometric estimation of hepatocytes DNA in chronic liver diseases including schistosomiasis for detection of early preneoplastic changes, J. Egypt. Soc. Parasitol. 24 (1994), 633641.

[3] H.M. Abdel-Rahman, A.M. El-Sahly, A.F. Khalafallah and R. Anwar, Serum prealbumin in schistosomiasis, J. Egypt Med. Assoc. 63 (1980), 135-140.
[4] A.M. Amin and E.G. Mikhail, Experimental schistosomiasis mansoni: Electrophoretic studies on serum proteins before and after administration of Oxamniquine, J. Egypt. Soc. Parasitol. 19 (1989), 447-460.

[5] J.D. Artiss, S. Vinogradoy and B. Zak, Quantitative determination of iron in serum, Clin. Chem. 14 (1981), 311-322.

[6] D.R. Baker, Capillary electrophoresis, Br. J. Exp. Pathol. 54 (1995), 409-415.

[7] W.F. Balistreri and R. Rej, Liver Functions, in: Tietz fundamentals of Clinical Chemistry, (4th ed.), C.A. Burtis and E.R. Ashwood, eds, W.B. Saunders Company, Philadelphia, 1996, pp. 539-567.

[8] R. Bergquist, Prospects of vaccination against schistosomiasis, Scand. J. Infec. Dis. 76 (1990), 60-71.

[9] D. Bout, R. Rousseaux, Y. Carlier and A. Capron, Kinetics of classes and subclasses of total immunoglobulins and specific antibodies to S. Mansoni during murine infection, Parasitology 8 (1980), 247-256.

[10] E. Coodley, Enzyme diagnosis in hepatic disease, Am. J. Gastroenterol. 56 (1971), 413-418.

[11] M.A. Darwish, R. Faris, J.D. Clemen, M.R. Rao and R. Edelman, High seroprevalence of hepatitis A, B, C and E viruses in residents in an Egyptian village in the Nile Delta, Am. J. Trop. Med. Hyg. 57 (1997), 251-278.

[12] M.A. Darwish, T.A. Raouf, P. Rushd, N.T. Constantine, M.R. Rao and R. Edelman, Risk factors associated with a high seroprevalence of hepatitis $\mathrm{C}$ virus infection in Egyptian blood donors, Am. J. Trop. Med. Hyg. 49 (1993), 440-447.

[13] A. Davis, Schistosomiasis, in: Mansons Tropical Diseases, (20th ed.), G.C. Cook, ed., W.B. Saunders Company, Philadelphia, 1996, pp. 1432-1433.

[14] M.A. El-Guinidy, M.A. El-Touny, M.A. Abdel-Bary, S.A. Abdel-Fattah and A. Metwally, Clinical and pharmacokinetic study of praziquantel in Egyptian schistosomiasis patients with and without liver cell failure, Am . J. Trop. Med. Hyg. 51 (1994), 809-818.

[15] A.M. ElHawary, A.M. Ibrahim, M.M. Shakir and M. Saif, Immunoelectrophoretic studies on serum proteins in bilharzial patients, J. Egypt., Med. Ass. 55 (1972), 23-33.

[16] A.M. El-Hawey, M.M. Abdel-Rahman, M.S. Ibrahim, A.H. Abdel-Rahman and M.M. Salama, Delta virus versus HBsAg in chronic active hepatitis and their relation to clinical, laboratory and morbidity findings in bilharzial and non bilharzial patients, J. Egypt. Soc. Parasitol. 23 (1993), 151-160.

[17] A.M. El-Ridi, M.A. Mansour and L.A. Aboul-Magd, Evaluation of serum cholinesterase and albumin in bilharziasis, $J$. Egypt. Soc. Parasitol. 17 (1987), 707-712.

[18] A. El-Rouby, S. El-Ashmouny, M. Salem, S. Hunter and N. ElBadrawy, Serum gamma- glutamyltranspeptidase activity in hepatosplenic schistosomiasis, Med. J. Cairo Univ. 52 (1984), 309-324.

[19] H.F. El-Sayed, S.M. Abaza, S. Mehanna and P.J. Winch, The prevalence of hepatitis $\mathrm{C}$ and infections among immigrants to a newly reclaimed area endemic for schistosoma mansoni in Sinai, Egypt. Acta Trop. 68 (1998), 229-235.

[20] A.R. El-Zayadi, O. Selim and E.H. Ibrahim, Does schistosomiasis play a role in the high seroprevalence of $\mathrm{HCV}$ antibody among Egyptians, Hepatol. 14 (1997), 417-422.

[21] P. Esterre, J.L. Pecarrere, J. Serieye, V.A. Ravalimalaa and J. Roux, History of hepatic lesion: Schistosoma mansoni bilharziasis, Arch. Inst. Pasteur (Madagascar) 61 (1994), 31-46.

[22] A.S. Evans and M.A. Stirewalt, Serologic reaction in S mansoni infections III. Ionographic fractionation of sera of mice with progressive disease, Exp. Parasitol. 6 (1957), 8-17. 
[23] F. Farinati, R.D. Cardin, A. Errico, N. Demaria, R. Naccorato, A. Cecchetto and W. Grigioni, Hepatocyte proliferative activity in chronic liver damage as assessed by the monoclonal antibody MIBI Ki67 in archival material: The role of etiology, disease activity, iron and lipid peroxidation, Am. Assoc. Hepatol. 23 (1996), 1468-1475.

[24] M.A. Gerber and S.N. Thung, Immunopathology of hepatitis C. Immunology and liver falk symposium No 70, Basel, Abstract Book, 1992, pp. 19-20.

[25] M.H. Ghanem, F.K. Guirgis and M. El-Sawy, Assessment of liver functions in bilharzial hepatic fibrosis, Alex. Med. J. 16 (1970), 177-182.

[26] E. Gindler, Quantitative determination of magnesium in serum, Clin. Chem. 17 (1971), 662-670.

[27] J.Y. Guh, Y.H. Lai and C.Y. Yang, Impact of decreased serum transaminase levels on the evaluation of viral hepatitis in hemodialysis patients, Nephron 69 (1995), 459-465.

[28] R.G. Hibbs, A.L. Gorwn, N. Hassan, M. Kamal and M. Darwish, The epidemiology of antibody to hepatitis C in Egypt, J. Infect. Dis. 168 (1993), 789-790.

[29] A. Hiller, J. Plazin and D.D. Van Slyke, Quantitative determination of total protein concentration in serum or plasma by a timed-endpoint Biuret method, J. Biol. Chem. 176 (1948), 1401-1406

[30] K.H. Isselbacher and D.K. Podolosky, Liver and biliary diseases, in: Harrisons Principles of Internal Medicine, K.J. Isselbacher, E. Brauwald, J.D. Wilson, J.B. Martin, A.S. Fauci and D.L. Kasper, eds, McGraw-Hill, New York, 1994, pp. 1438-1448.

[31] K. Jendrassik and T. Gros, Colorimetric determination of serum plasma total and direct bilirubin, Biochem. 297 (1938), 81-89.

[32] R.J. Johnson, D.R. Gertch and W.C. Couser, Hepatitis C virusassociated glomerulo-nephritis, effect of alpha interferon, Kid. Inter. 46 (1994), 1700-1704.

[33] M.M. Kaplan, Laboratory tests, in: Diseases of the Liver, (7th ed), L.R. Sciff and E.R. Schiff, eds, J.B. Lippincott Company, Philadelphia, 1993, pp. 108-144.

[34] H. Liehr, R. Seelig and H.P. Seelig, The clinical behaviour of immunology unique courses of NANB hepatitis, Z. Gastroen- terol. 20 (1982), 278-285.

[35] A.M. Masoud, M.M. Hussein, M.E. Anwar, M. Ashour, E.A. El-Fekhakh and E.W. Fahmy, Gastric histochemical studies in endemic schistosomal hepatosple-nomegaly, J. Egypt. Soc. Parasitol. 18 (1988), 599-607.

[36] J.P. McKenna, M. Moskovit and J.L. Cox, Abnormal liver function tests in asymptomatic patients, Am. Fam. Phys. 39 (1989), 117-121.

[37] P. Mathurine, J. Moussalli, J.F. Codranel, V. Thibault, F. Charlotte, P. Dumouchel, A. Cazier, J.M. Huraux and T. Poynard, Slow progression rate of fibrosis in hepatitis $\mathrm{C}$ virus patients with persistently normal alanine transaminase activity, Am. Ass. Hepatol. 27 (1998), 868-871.

[38] P.P. Michielsen, E.I. Hauben, A.M. Ramon, E.A. Van Mark and P.A. Pelckmans, Serum aminotransferase levels and histological disease in chronic hepatitis C, Acta Gastroenterologica (Belg.) 60 (1997), 11-15.

[39] W. Moussa, C.I. Waslien and M.M. Mansour, Serum glycoproteins in schistoso-miasis, Am. J. Trop. Med. Hyg. 25 (1976), 57-59.

[40] R.S. Murray, Schaum s Outline Series of Theory and Problems of Probability and Statistics, McGraw-Hill Book, Company, Singapore, 1982.

[41] R. Preising, Clinical Evaluation of Liver Function, in: Recent Advances in Hepatology, M.C. Thomas and F.A. Jones, eds, Churchill Livingstone, London, 1986, pp. 105.

[42] S.E. Ritzman, J.C. Daniels and L.P. Cawley, Serum protein abnormalities: Diagnostic and clinical aspects, Little Brown Co, Boston, 1975, pp. 3.

[43] P.J. Scheuer, P. Ashrafzadeh, S. Sherlock, D. Browm and G.M. Dusheiko, The pathology of hepatitis C, Hepatology 15 (1992), 567-571.

[44] S. Sherlock, Virus Hepatitis, in: Diseases of the Liver and Biliary System, (6th ed.), Blackwell Scientific Publication, London, 1981, pp. 260-292.

[45] S.G. Sheth, S.L. Flamm, F.D. Gordon and S. Chapra, AST/ALT ratio predicts cirrhosis in patients with chronic hepatitis C virus infection, Am. J. Gastroentrol. 93 (1998), 44-48.

[46] E. Wong, Estimation of hemoglobin by the determination of blood total iron, J. Biol. Chem. 77 (1928), 409-414. 


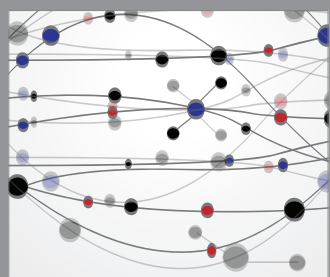

The Scientific World Journal
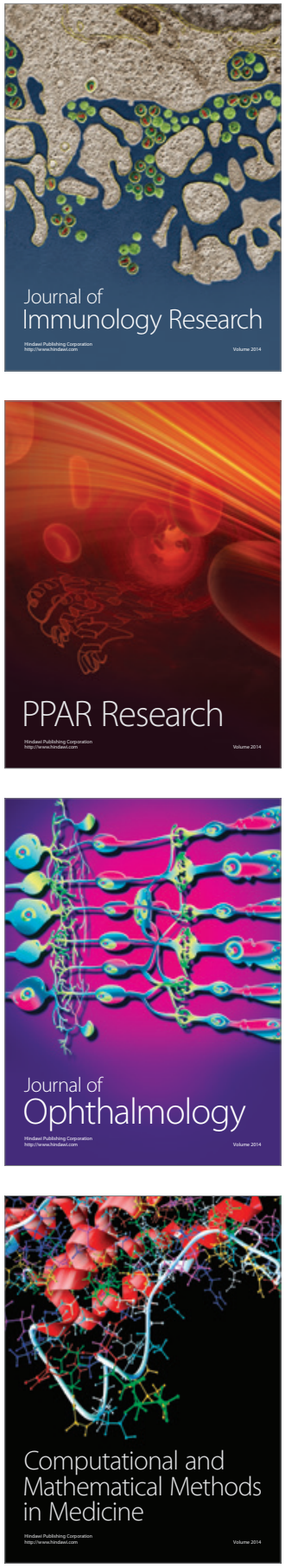

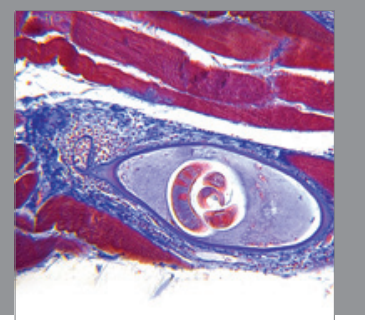

Gastroenterology

Research and Practice
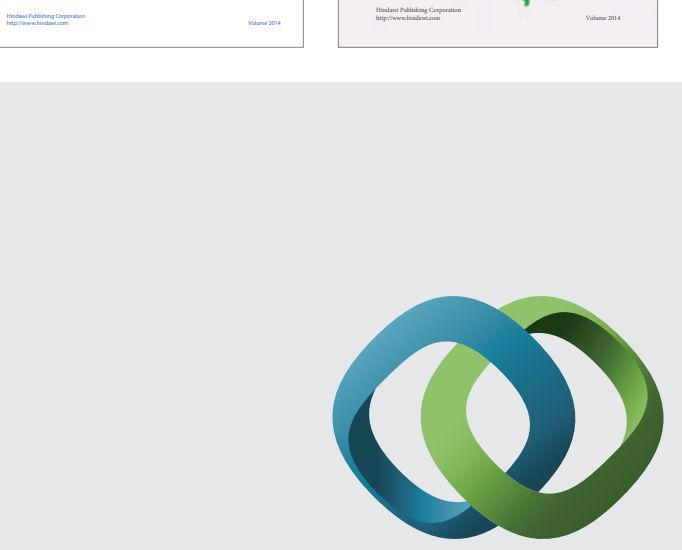

\section{Hindawi}

Submit your manuscripts at

http://www.hindawi.com
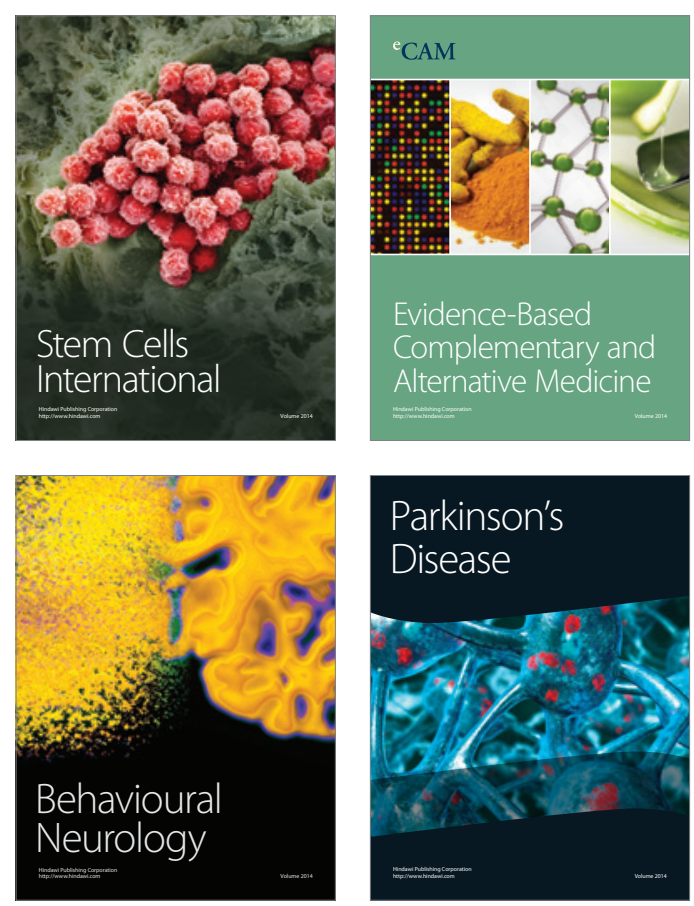

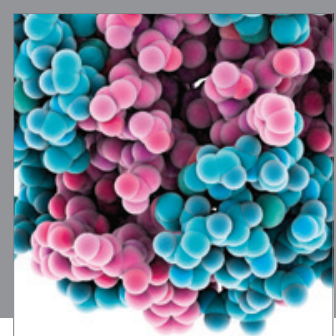

Journal of
Diabetes Research

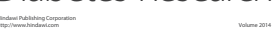

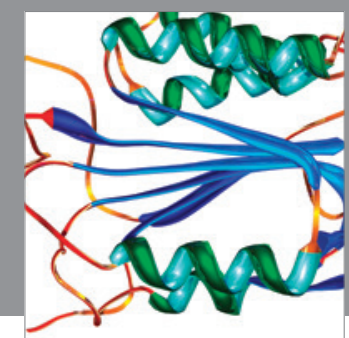

Disease Markers
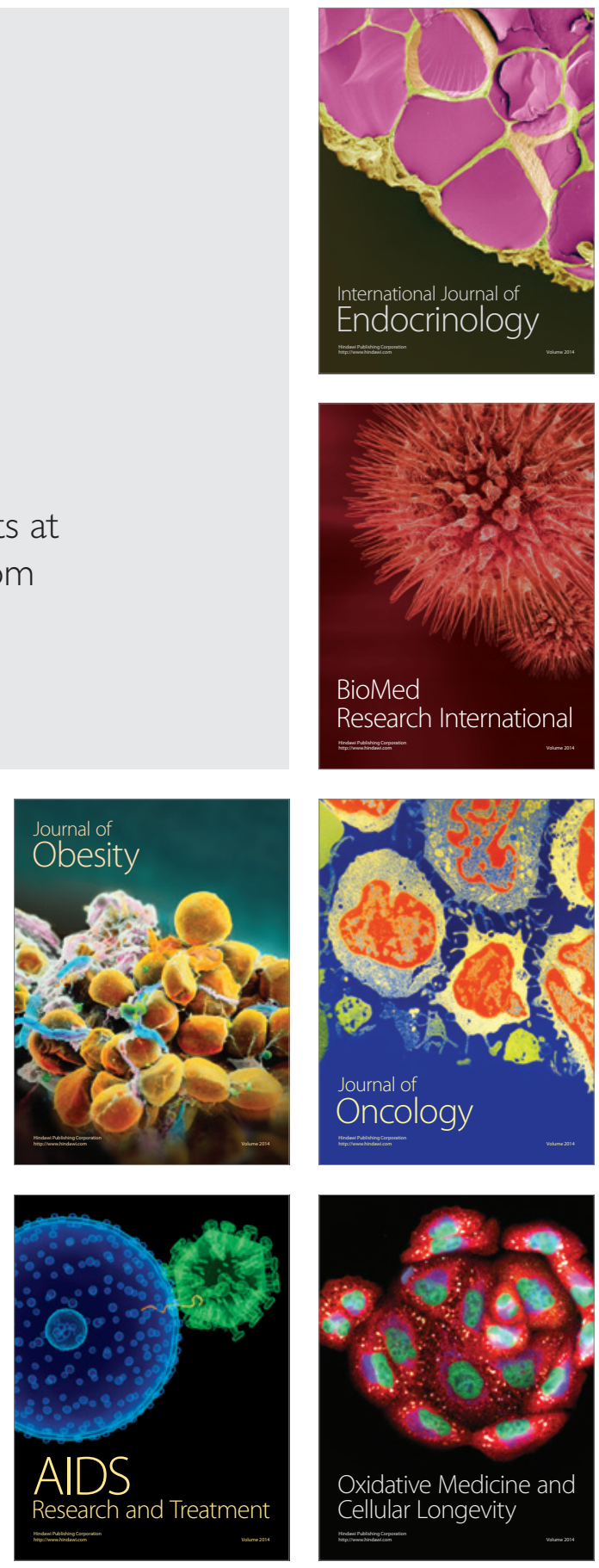